\title{
Implementation of Interactive Learning Media on Chemical Materials
}

\author{
Patson Mweene ${ }^{1}$, Gideon Muzaza ${ }^{1}$ \\ ${ }^{1}$ Department of Primary Education, University of Zambia, Zambia \\ *Corresponding Author: Patson Mweene
}

\begin{abstract}
This paper aims to identify the implementations of interactive learning media on chemical materials based onf android, web and software to improve the learning media in the class. Learning media is one of the learning components that has an important role in Teaching and Learning Activities. The use of media should be a part that must get the attention of the teacher/facilitator in every learning activity. Therefore, the teacher/facilitator needs to learn how to determine learning media in order to make the achievement of learning objectives effective in the teaching and learning process.
\end{abstract}

Keywords: Learning Media, Interactive, Android, Software, Web

\section{Introduction}

The development of science and technology has brought very significant changes to various dimensions of human life, both in economic, social, cultural and educational aspects. Therefore, so that education is not left behind from the development of science and technology, adjustments are needed, especially those related to teaching factors in schools. One of these factors is learning media that need to be studied and mastered by teachers / prospective teachers, so that they can convey subject matter to students in an efficient and effective manner.

In fact, learning media are often neglected for various reasons, including: limited time to prepare for teaching, difficulty finding the right media, unavailability of funds, and so on. This actually does not need to happen if every educator / facilitator already has knowledge and skills regarding instructional media. Given the large role of media in learning this paper is expected to help us as prospective teachers in getting to know various learning media and their characteristics and are used for us to teach for in the future.

\section{Android-Based Interactive Learning Media (Microsoft Office Power Point)}

Power Point is one of the programs in Microsoft Affice. Power Point or Microsoft Office PowerPoint is "a computer program for presentations". Microsoft Office Power Point is an application program specifically designed to display multimedia programs. This is as stated by Sundari (2008) namely "Microsoft Office Power Point program is a software specifically designed to be able to display multimedia programs attractively, easy to manufacture, easy to use and relatively cheap because it does not require raw materials other than tools to store data". There are strengths and weaknesses which is; (1) Excess, Microsoft Power points in the teaching and learning process have several advantages including; (a) The presentation is interesting because there are games of color, letters and animations, text animations and 
animated images or photos. (b) More stimulating children to find out more information about the teaching materials presented. (c) Information messages are visually easy for students to understand. (d) Educators do not need to explain much of the teaching materials that are being presented. (e) Can be reproduced as needed, and can be used repeatedly. (f) Can be stored in the form of optical or magnetic data. (CD / Diskette / Flashdisk), so it's practical to carry everywhere. (2) Disadvantages, microsoft Power point has several drawbacks including: (a) There must be sufficient preparation that takes up time and effort. (b) If a PC is used for presentations in class, then the educators must be bothered by the transportation and storage of the PC. (c) If the monitor screen used is too small (14 "-15"), it is likely that students sitting far from the monitor have difficulty seeing the teaching materials displayed on the PC. (d) Educators must have sufficient abilities to operate this program, so that the presentation will not be too obstructed.

\section{Software-Based Interactive Learning Media (Chemsketch)}

Increasingly, more and more developments are happening in the world, including developments in science, where everyone is competing to make tools that can make it easier to do something. Current technology allows people to no longer need to come to the lecturer to collect assignments, simply by uploading or sending assignments via e-mail or otherwise using an internet connection. These advances also require humans to follow its developments, including in chemistry. Creating compound structures now doesn't have to be done by writing on paper manually (Tetko et al., 2005). Chemical structures can be created using software that provides services for drawing structures so that they can be sent over the internet. One of the software that can be downloaded for free or freeware is ACD / Chemsketch (Ihlenfeldt et al, 2009). According to Li et al (2004) ACD / Chemsketch is a software used to draw chemical structures including organic chemistry, organometallics, polymers and Markush structures. Chemsketch software can describe chemical structures in 2D and 3D. This software can be used to create good structures and diagrams for reports. This software is very easy to use by simply clicking and dragging the available tools to draw the desired structure. This program also provides structures for amino acids, alkaloids, carbohydrates, nucleic acids, DNA / RNA, laboratory equipment in the form of glasses, orbitals, steroids, terpenes and others stored in the templates menu. The software also provides curves and graphs. Chemsketch is issued by ACD / Labs.com which can be downloaded for free.

The features contained in Chemsketch include: (1) Form and view structures in 2D (2 dimensions) or create 3D shapes so that they can be viewed from various angles. (2) Draw reactions and calculate the quantity of reactants.(3) Generates structures from InChI. (4) Generates systematic names (IUPAC) for a variety of molecules up to 50 atoms and 3 rings (cyclic). (4) Predicts log P for individual structures. (5) Chemsketch provides more than 165 thousand structures with systematic and nontrivial names.

ChemSketch software can run like any other program on a computer, before that, the software user must first install the ChemSketch software. How to start the ChemSketch program that has been installed, namely from the windows menu click start, then click program, select ChemSketch then the ChemSketch program window will open. Drawing a molecule in 3D (for example a $\mathrm{CH} 4$ molecule) can be rotated to provide a complete picture by opening the Chemsketch application that has been installed. Click Atom C on Structure Mode on the left tool and click once on the work area to generate the molecular formula $\mathrm{CH} 4$. Add 
hydrogen explicite from the Tools menu to create a structural formula stretch, select the structural formula, click the Tools menu and select Strucutre Properties then a pop up menu will appear and on the Common tab check All Show Carbons. Optimize the 3D structure by clicking the Tools menu then clicking 3D structure optimization, if there is an option (click yes to remove the $\mathrm{H}$ atom during the 3D optimization), then open the 3D Viewer Acd Lab from the Start menu. Return to Chemsketch 2D to copy 2D to 3D. Rotating can show various properties of molecular shape such as bond lengths and angles formed by 3 atoms with this ChemSketch.

Examples of Media Application in Class 11 Chemical Hydrocarbon Compound Structure Materials : (1) Open ChemSketch from Star-Program-ACDLabs12-Chemsketch. In standard condition (default) ChemSketch is in Structure mode. (2) In order for all C atoms to appear later, please set their properties from Tools-Stucutures Properties. How to Check All on Show Carbons on the Common tab. (3) Make sure you are in Stucture mode and not in Draw mode. (4) Click Atom C on the menu on the left side of the chemsketch work screen. Drag then click once to create a $\mathrm{C}$ (methane) and drag again by connecting that first $\mathrm{C}$ and click to add a $\mathrm{C}$ atom to become ethane. And so on, to create a branch, just click on. (5) The main $C$ which will be used as a branch then drag and click.

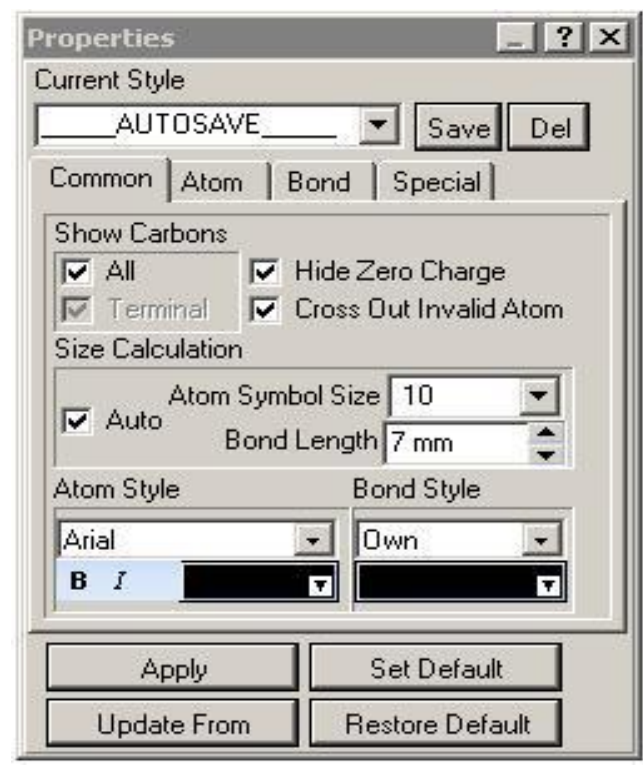

Figure 1. Chemsketch seting

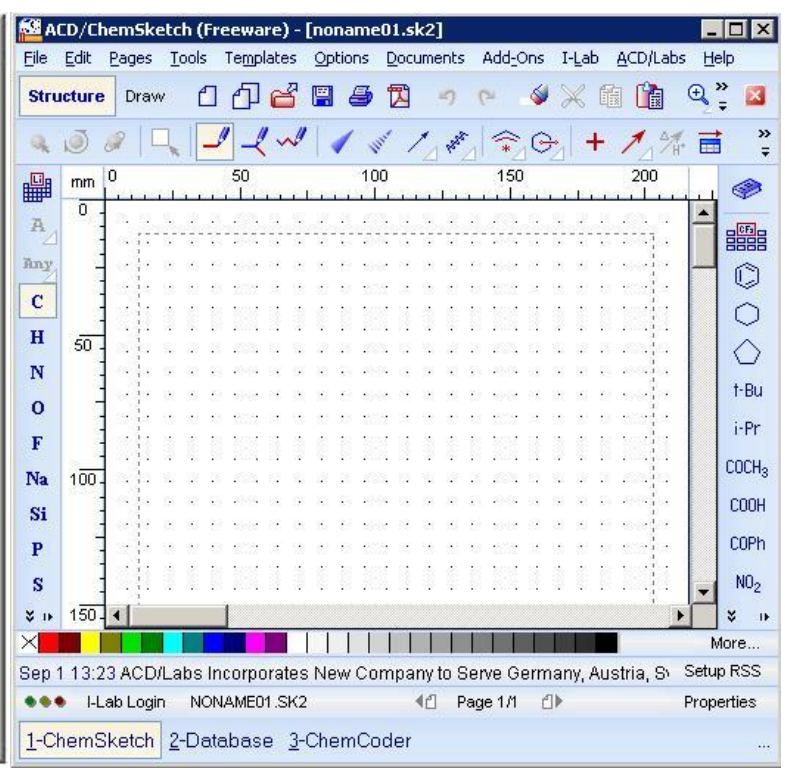

Figure 2. Chemsketch

(6) Make sure the structural formula drawn in the previous step is selected, if not, click on the toolbar just below the draw mode writing. Then perform a structure selection for the purpose of displaying an expanded structure with $\mathrm{H}$ and $\mathrm{C}$ atoms visible. The trick is to click Tools-Add explicit hydrogens. If successful, it looks like this. (7) To copy it so that it can be copied into Microsoft Word, switch it from Structure mode to Draw mode. (8) Copy the finished structural formula then place it (paste / paste) it into Microsoft Word.

\section{Strengths and Weaknesses}

The advantage of using Chemsketch is that you can visualize chemical structures in a 2dimensional (2D) or 3-dimensional (3D) plane with the hope of gaining more knowledge about spatial configuration and the relationship between molecular properties. Chemsketch can also check other tautomer forms of structures that have been created. The shape of the 
tautomer is very important for the search for structure, prediction of pKa and psychochemical properties, as well as interpretation or translation (NMR, MS and other analytical data). ACD / Labs software can assist in teaching chemistry concepts to high school, undergraduate, and graduate chemistry students. Students or students also get the benefit of using ACD / Chemsketch while studying, so that it can be used as experience while in the world of work. Weaknesses, Chemsketch's weakness is that the resulting image has a resolution that is not so large that when printed the results are not good (Marpaung et al., 2020).

\section{Web-Based Interactive Learning Media / Online Site (Google Classroom)}

Google Classroom is a free web service, developed by Google for schools, that aims to simplify creating, distributing and grading assignments without having to be face to face. Google Classroom's main goal is to streamline the process of sharing files between teachers and students. Google Classroom combines Google Drive for assignment creation and delivery, Google Docs, Sheets, and Slides for writing, Gmail for communications, and Google Calendar for scheduling. Students can be invited to join classes via a private code, or automatically imported from the school domain. Each class creates a separate folder in each user's Drive, where students can submit work for teachers to grade. The mobile app, available for iOS and Android devices, lets users take photos and attach assignments, share files from other apps, and access information offline. The teacher can monitor progress for each student, and once assessed, the teacher can return to work together via comments (Olson \& Zinda, 2008).

Examples of Media Application in the Material Theory of Atomic Chemical Model Development for Class 10. (1) Create a class for the theoretical material of the atomic model development by opening classroom.google.com. (2) At the top of the Classes page, click Add Create class.(3) Enter the class name of the Atomic Model Theory of Development.

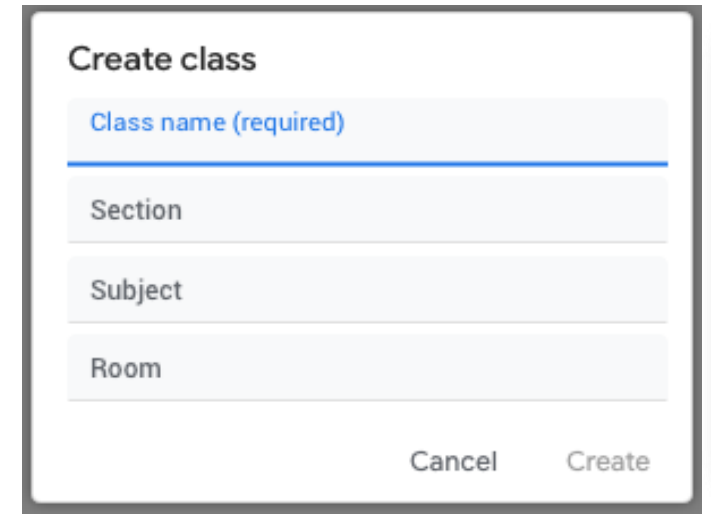

Figure 3. GC Setting

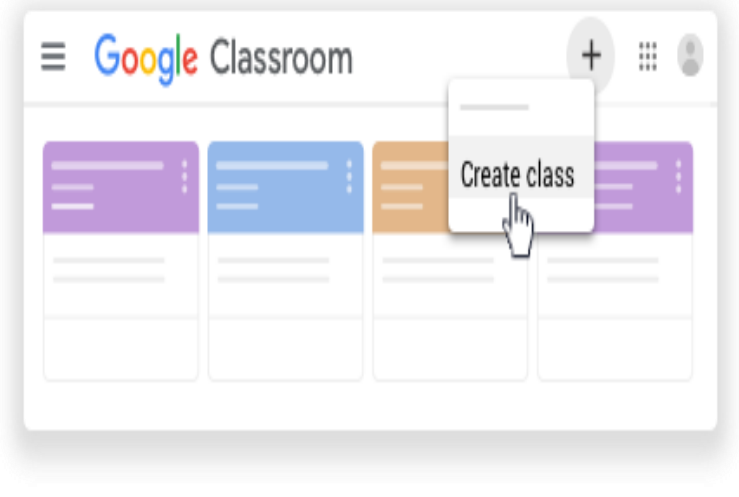

Figure 4. Google Classroom

(4) (Optional) To enter a brief description, class level, or class schedule, click Section and enter details. (5) (Optional) To add a subject, click Subject, then enter a name or click a name from the list that appears when entering text. (5) (Optional) To enter the location of the class, click Room and enter details. (6) Next, click Create. (7) To add students to the class, copy the class code and distribute it to students. (8) After students get the code, go to classroom.google.com, then click Login. Sign in with a Google Account. (9) At the top, click Join class. Enter the class code from the teacher, then click Join. (10) Learning the theory of the development of the atomic model is ready to start. 


\section{Strengths and Weaknesses}

Excess, (1) Very mobile Friendly for beginners, the first advantage is that it is very mobile friendly for beginners, meaning that people who are using Google Classroom for the first time will definitely have no difficulty operating it. Google itself is very concerned about the comfort of its users. So Google Classroom is designed with a simple but many features. So naturally, people who are new to this application can use it immediately. (2) Easily manage assigned tasks, besides being easy to use, there are other features in Google Classroom where when we are given assignments by our teachers or class admins, we can easily see them on a page that provides an assignment page. That way we don't have to bother looking for what the admin or teacher has assigned us to do. So it's worth it if Google Classroom becomes an alternative application for learning online or online. Google Classroom has made it easy for both students and teachers. (3) All files go to our Google Drive, the third advantage of Google Classroom is that all files, be it mp4, mp3, doc, pdf, zip and many more. All of that automatically goes to our Google Drive account so we don't have to look for other storage to store the files we have uploaded. So don't worry about losing files or other documents. It's all stored in Google Drive. (4) Easily review assignments before they are send, reviewing the assignment is very necessary, because we can see what errors or shortcomings still exist in the assignment we will send. So Google Classroom provides a feature to view assignments before they are sent. Every learning application should provide features such as those of Google Classroom to make it easier to review our assignments. (5) It's easy to see the announcement from the teacher, announcements in Google Classroom are intended so that teachers can provide information, be it attendance, assignments, student photos or other important announcements, making it easier for teachers to send assignments on the Google Classroom page. Don't bother sending announcements via SMS or online messages anymore. The advantages in terms of announcements are also supported by the ease of discussion. Because Google Classroom provides discussion space in the comments column so that we can discuss and are free to send files to discuss. (6) Ad-free and safe, the advantage that we can feel when using GC (Google Classroom) is that all the activities we do will not be disturbed by ad serving. So that we focus more on learning and discussing in Google Classroom. Without having to worry about the number of ads that appear. All ads, whether paid or not, are not in Google Classroom. (7) Available for free 100\%, of the most applications that we can download for free, you will find the Google Classroom application which is available for free either on the playstore or the app store. We can download it freely anytime and it's more efficient. Google Classroom is an application that is $100 \%$ free without having to pay (Boekaerts, 2002)

Disadvantages: (1) Display that is less attractive to students, the disadvantage of Google Classroom is that it looks less attractive. It only displays a few choices of images and it is only a cartoon image. Classroom should provide an image for the class to be even more attractive so that students studying in Google Classroom do not feel bored. With the appearance as it is, maybe for some people it doesn't matter but for those who like beauty it is necessary. (2) When Google Drive is Full the files cannot be sent. The weaknesses and weaknesses of Google Classroom that are very visible are that if the Google Drive that we have is full, the files or documents that we send to the teacher will be errors and not sent. This is very annoying for a student and results in him having to buy a new drive or install a new cloud storage or cloud storage. Then connected to Google Classroom first before using Google Classrom so that it can be used. (6) Delivery time can still be arranged, if we want to send 
files to Google Classroom, we can set the delivery time. That is, if we are late in sending files we can delay the time on our smartphones for a day so that we can submit our files, which could not be submitted because they were too late (Nguyen et al., 2018)

\section{Conclusion}

From this paper it can be concluded that interactive learning media to be applied in chemical materials can be divided into Android-based learning media that can be used by Microsoft Power Point, software-based learning media can use chemsketch and web-based learning media / online sites can use google classroom. It is better if an educator can choose and use learning media properly so that students are more enthusiastic in participating in the learning that is delivered and increase learning motivation in students.

\section{References}

Boekaerts, M. (2002). Bringing about change in the classroom: Strengths and weaknesses of the self-regulated learning approach-EARLI Presidential Address, 2001. Learning and instruction, 12(6), 589-604.

Ihlenfeldt, W. D., Bolton, E. E., \& Bryant, S. H. (2009). The PubChem chemical structure sketcher. Journal of cheminformatics, 1(1), 1-9.

Li, Z., Wan, H., Shi, Y., \& Ouyang, P. (2004). Personal experience with four kinds of chemical structure drawing software: review on ChemDraw, ChemWindow, ISIS/Draw, and ChemSketch. Journal of Chemical Information and Computer Sciences, 44(5), 18861890.

Marpaung, D. N., Siregar, L. F., \& Pongkendek, J. J. (2020, July). Effect of using chemsketch on teaching molecular shape of hydrocarbon to increase student's achievement. In Journal of Physics: Conference Series (Vol. 1569, No. 4, p. 042101). IOP Publishing.

Nguyen, G. T. K., \& Dinh, H. T. (2018, September). Advantages and Disadvantages of Using Google Classroom in Project-based Learning-A Case Study. In VietTESOL International Convention 2018.

Sundari, I. (2018). The Use Of Multimedia Power Point To Improve Students' Speaking Skills At The Eleventh Grade Of Sma N. 1 Air Joman.

Tetko, I. V., Gasteiger, J., Todeschini, R., Mauri, A., Livingstone, D., Ertl, P., ... \& Tanchuk, V. Y. (2005). Virtual computational chemistry laboratory-design and description. Journal of computer-aided molecular design, 19(6), 453-463. 